NIM Article PNNL-103824

\title{
Progress in Alternative Neutron Detection to Address the Helium-3 Shortage
}

Richard T. Kouzes ${ }^{1}$, Azaree T. Lintereur, Edward R. Siciliano

Pacific Northwest National Laboratory, MS K7-36, P. O. Box 999, Richland WA 99352 USA

Abstract

One of the main uses for ${ }^{3} \mathrm{He}$ is in gas proportional counters for neutron detection. Such detectors are used

8 at neutron scattering science facilities and in radiation portal monitors deployed for homeland security

9 and non-proliferation applications. Other uses of ${ }^{3} \mathrm{He}$ are for research detectors, commercial instruments,

10 well logging detectors, dilution refrigerators, lung imaging, for targets in nuclear research, and for basic

11 research in condensed matter physics. The supply of ${ }^{3} \mathrm{He}$ comes entirely from the decay of tritium

12 produced for nuclear weapons in the U.S. and Russia. Due to the large increase in use of ${ }^{3} \mathrm{He}$ for science 13 and homeland security (since 2002), the supply could no longer meet the demand. This has led to the 14 development of a number of alternative neutron detection schemes.

16 Keywords: neutron detection; helium-3; 3He; alternative neutron detectors

17

18 PACS: $29.40 .-\mathrm{n}$

\footnotetext{
${ }^{1}$ Corresponding Author: Phone: +1-509-372-4858; E-mail: rkouzes@pnl.gov
} 


\section{The ${ }^{3}$ He Shortage}

The light isotope of helium, ${ }^{3} \mathrm{He}$, is a noble gas found naturally at part per million levels in the solar wind, on the lunar surface, and from some underground gas sources [1]. The supply of ${ }^{3} \mathrm{He}$ has come under strict control since 2008 when it was realized that the supply was limited. The current world supply of ${ }^{3} \mathrm{He}$ comes entirely from the decay of tritium originating in the nuclear weapons programs in the U.S. and Russia [2]. Neutron detectors have been the major consumers of ${ }^{3} \mathrm{He}$ for the last few decades, particularly for neutron scattering science [3] and homeland security [4]. Other applications include research detectors, commercial instruments, well logging detectors, dilution refrigerators, lung imaging, for targets in nuclear research, and for basic research in condensed matter physics.

The sole method currently used to produce ${ }^{3} \mathrm{He}$ is collecting it as a byproduct from the radioactive decay of tritium, where it is separated during the tritium processing conducted at the National Nuclear Security Administration (NNSA) Savannah River Site in South Carolina. This tritium (12.4-year half-life) comes from the refurbishment and dismantlement of the U.S. nuclear stockpile. The U.S. ceased the production of tritium in 1988, and is currently developing methods for production of small quantities for weapons use only in the Watts Bar reactors in Tennessee. The production of tritium just for generating ${ }^{3} \mathrm{He}$ is cost prohibitive (the estimated cost of ${ }^{3} \mathrm{He}$ produced by making new tritium is $\$ 11 \mathrm{k}-18 \mathrm{k} /$ liter [5]).

From Savannah River, the ${ }^{3} \mathrm{He}$ is transferred to Linde Electronics and Specialty Gases (Munich, Germany) where it is purified and sold to customer or vendors for incorporation into products under direction from the federal government. While the supply of gas originates from NNSA, the Department of Energy (DOE) Isotope Program makes the ${ }^{3} \mathrm{He}$ available through an allocation process. In March 2009 , the U.S. Departments of Energy, Defense and Homeland Security formed an Integrated Product Team and agreed that an interagency group would make allocations [5]. In July 2009, an Interagency Policy Committee (IPC), reporting to the White House National Security Staff, was established. The DOE Isotope Program currently administers the policies set by the IPC (now known as the IAG or Interagency Working Group) for the allocation of the ${ }^{3} \mathrm{He}$. The following assumptions are made for federal allocations:

1. No more than 14000 liters per year will be made available from the federal supply.

The allocation policy established by the IAG gives the following priorities for allocation of the 10 kiloliters, in descending order:

1. Domestic requests championed through a federal agency have first priority:

a. Those programs requiring the unique physical properties of ${ }^{3} \mathrm{He}$ have first priority.

b. Those programs that secure the threat furthest away from U.S. territory and interests have second priority.

c. Those programs for which substantial costs have been incurred have third priority.

2. International requests championed through a federal agency have second priority:

a. ${ }^{3} \mathrm{He}$ will be used in an international research project with direct U.S. involvement. This provides direct benefit to U.S. researchers and the U.S. research enterprise.

b. $\quad{ }^{3} \mathrm{He}$ will be used at a scientific facility for which there is U.S. research participation. This provides direct benefit to the U.S. research enterprise and it will contribute positively to international cooperation and relations. In addition, the research complements that carried out 
by U.S. scientists and has strong U.S. support.

c. ${ }^{3} \mathrm{He}$ will be used by an international entity for research that does not directly involve U.S. scientists but the research complements that carried out by U.S. scientists and has strong U.S. support. This provides an indirect or direct benefit to the U.S. research enterprise and it will contribute positively to international cooperation and relations.

The U.S. inventory of ${ }^{3} \mathrm{He}(\sim 260 \mathrm{~kL}$ in 2003$)$ is slowly being depleted. The only other world supplier of ${ }^{3} \mathrm{He}$ is Russia, which has been providing about the same amount as the U.S. to the open market. The U.S. imported about $25 \mathrm{~kL} / \mathrm{y}$ from Russia between 2004 and 2008 [5]. Prior to FY09, the DOE brokered 60 $\mathrm{kL} / \mathrm{y}$ of ${ }^{3} \mathrm{He}$ for the several previous years, which decreased the accumulated supply.. In recent years, the DOE has allocated $\sim 10 \mathrm{~kL} / \mathrm{y}$ for federal use, and $\sim 4 \mathrm{~kL} / \mathrm{y}$ for public auction; actual distribution and use has been far less. Between 2003 and $2008,{ }^{3} \mathrm{He}$ sold for $\$ 40-85$ per liter, whereas in 2012 the price had risen to about $\$ 765$ per liter for federal use and about $\$ 2500$ per liter for commercial use [6].

For a worst-case hypothetical scenario for the U.S. ${ }^{3} \mathrm{He}$ supply that assumes a $4 \mathrm{~kL} / \mathrm{y}$ public auction and $10 \mathrm{~kL} / \mathrm{y}$ federal use, the supply would be depleted by about the year 2024. Figure 1 shows another hypothetical scenario that assumes no auction and only the actual projected federal use, which is less than $10 \mathrm{~kL} / \mathrm{y}$. It also assumes two new increases in supply of about 8000 liters in both 2014 and 2024. Under this scenario, the supply lasts past the year 2040. There is thus a great uncertainty about how long the supply will actually last [7]. Any new supplies of ${ }^{3} \mathrm{He}$, such as CANDU reactors or cryogenic separation from natural gas or $\mathrm{CO}_{2}$ wells, is being left to private industry to develop.

\section{Neutron Detection Options}

Neutron detection is based on gas counters, scintillators, or semiconductors, as summarized in a review article [8]. Detection alternatives for neutron scattering science have undergone active research around the world, for example in reference [3]. There is still a great need to build alternatives that address the unique needs of the neutron scattering science community. Detection alternatives for homeland security have been under rapid development since 2008, especially for radiation portal monitor applications [9]. The heightened activity to find alternatives for radiation portal monitors has led to several commercial replacements that have been fielded, and thus, in the opinion of the authors, solving this need.

The characteristics of any neutron detection system are: neutron detection efficiency, gamma-neutron separation [10], commercial availability, and robustness for deployment. It is very difficult to meet the performance capability of ${ }^{3} \mathrm{He}$ for neutron detection, and there are no existing replacements that combine all the capabilities of ${ }^{3} \mathrm{He}$ [11]. However, a variety of ${ }^{3} \mathrm{He}$ alternatives are available to meet different needs. These technologies include:

- $\mathrm{BF}_{3}$ filled proportional counters. These tubes are a direct physical replacement for a ${ }^{3} \mathrm{He}$ tube, but are limited to about one atmosphere and have inherently lower neutron sensitivity (the ${ }^{10} \mathrm{~B}$ crosssection $70 \%$ that of ${ }^{3} \mathrm{He}$ ), meaning several tubes are needed to replace one ${ }^{3} \mathrm{He}$ tube [12][13]. Another drawback of this alternative is the toxicity of $\mathrm{BF}_{3}$. When a neutron is captured on ${ }^{10} \mathrm{~B}, \alpha$ and ${ }^{7} \mathrm{Li}$ ions are produced. The gamma ray rejection capability of $\mathrm{BF}_{3}$ is even better than that of ${ }^{3} \mathrm{He}$. There is at least one U.S. supplier of $\mathrm{BF}_{3}$ tubes.

- Boron-lined proportional counters. These tubes are also a direct physical replacement for a ${ }^{3} \mathrm{He}$ tube and avoid the hazardous characteristic of $\mathrm{BF}_{3}[14][15]$. However, they have much lower sensitivity than ${ }^{3} \mathrm{He}$ tubes since only the inner surface of the tube is active and the boron layer is limited to a few microns in thickness due to the range of the $\alpha$ and ${ }^{7} \mathrm{Li}$ ions. The tubes use an inert atmosphere proportional gas and have good gamma ray rejection capability. Tubes vary in size between a few millimeters (straw tubes) to several centimeters in diameter [16] and may have position sensitivity for neutron scattering science applications [17]. There are at least three U.S. suppliers of boron-lined tubes, and one supplier of parallel plate proportional detectors. 
- $\quad$ Glass fibers loaded with ${ }^{6} \mathrm{Li}$. The ${ }^{6} \mathrm{Li}$-enriched lithium silicate glass fiber technology was developed at Pacific Northwest National Laboratory and was commercialized. An assembly can have comparable sensitivity to a ${ }^{3} \mathrm{He}$ assembly [18][19][20]. When a neutron is captured on ${ }^{6} \mathrm{Li}, \alpha$ and ${ }^{3} \mathrm{H}$ ions are produced. The disadvantage of this technology is the neutron-gamma ray separation, based on pulse shape analysis, is not adequate for some applications.

- Light guides with $\mathrm{ZnS}$ scintillator and ${ }^{6} \mathrm{LiF}$. This technology is available from several vendors and has good sensitivity and adequate neutron-gamma separation depending on the analysis method used [21]. These systems are being applied to neutron scattering science, see for example [22], safeguards [23], and national security [24]. There are several vendors of this technology.

- Crystalline neutron detectors. For example, LiI:Eu is a well known inorganic scintillator that is sensitive to neutrons. Newer scintillators like $\mathrm{SrI}_{2}: \mathrm{Eu}$ [25] and CLYC $\left(\mathrm{Cs}_{2} \mathrm{LiYCl}_{6}: \mathrm{Ce}\right)$ [26] are becoming commercially available. These respond to gamma rays and neutrons, and separation of neutrons and gamma rays relies upon pulse shape analysis. There are several commercial suppliers of such scintillators.

- Doped scintillators. There are various options for making liquid, plastic or glass scintillators doped with neutron capture materials (Li or B) [27]. The major drawback in this approach is that they tend to have poor neutron-gamma ray separation.

- Neutron-capture gamma-ray detectors. Such systems rely upon the $2.2 \mathrm{MeV}$ gamma ray following neutron capture on hydrogen, or similar gamma rays from neutron capture on other elements [28]. Demonstration systems of such detectors tend to have too low a neutron detection efficiency and suffer from the same gamma ray background problem as doped scintillators.

- Semiconductor neutron detectors. There are a few semiconductor detectors that have been demonstrated that utilize a neutron capture material as the detector or on the semiconductor surface (e.g., coated Si, GaAs, boron carbide) [29]. Research on this technology has generated small detectors.

- Foil detectors. Various geometries of gas detectors operating in the ionization or proportionalregime utilizing neutron absorbing materials have been demonstrated. These have multi-wire [30] or gas electron multiplier (GEM) [31] readout methods.

- Fission chambers. Such systems use fissionable material to capture neutrons, tend to be small, and are used for internal monitors in reactors [32].

Available technologies for fast neutron detection include:

- Liquid scintillators. Liquid scintillators have long been used for fast neutron detection, relying on pulse shape discrimination to differentiate between gamma ray interactions and recoil protons from neutron interactions. New non-flammable liquid scintillators are being explored for coincidence counters for safeguards where their very fast response is an advantage for coincidence analysis [33]. Liquid scintillators are sensitive to neutrons with energies above a few hundred $\mathrm{keV}$ and pulse shape analysis is used to separate gamma ray and neutron signals.

- Plastic scintillator. Plastic scintillator is sensitive to the recoil protons produced by fast neutrons. The disadvantage is the much greater gamma ray sensitivity [34]. Recent advances have been made in producing plastic with neutron-gamma ray discrimination.

- High-pressure ${ }^{4} \mathrm{He}$ filled detectors. Neutron interactions in ${ }^{4} \mathrm{He}$ produce recoils that produce scintillation light that can be observed with phototubes [35]. The advantage of this approach is low sensitivity to gamma rays.

- Bubble detectors. Bubble and tensioned-fluid detectors have a long history, but have been 
updated for use in dark matter and neutron detection. These detectors can have large volumes and generally rely on acoustic readout of the sound made by bubble formation [36]. The advantage of this approach is almost total lack of sensitivity to gamma rays. Their disadvantage is count rate limitations.

\section{Conclusions}

Thus far there appears to be no existing alternative that combines all the capabilities of ${ }^{3} \mathrm{He}$ for neutron detection efficiency, gamma-neutron separation, commercial availability, and robustness for deployment. In response to its eventual loss, a great deal of work has gone into finding alternative technologies. Some of the alternatives have existed for many years, but a number of new scintillators have been developed. Solutions for replacement of ${ }^{3} \mathrm{He}$ depend strongly on the application. Several replacements for large sized neutron detectors for homeland security have been developed and fielded. Developments are under way for the diverse needs of neutron scattering science where detectors will be needed for new facilities over the next decade, especially in Europe and Asia. Safeguards is another area of active development where coincidence counters and multiplicity detectors based on alternatives are actively being pursued to fill future needs. A lot of effort is now centered on development and improvement of new neutron-sensitive solid scintillator materials that depend on pulse shape discrimination for separation of gamma ray and neutron pulses.

\section{Acknowledgements}

Pacific Northwest National Laboratory is operated for the United States Department of Energy by Battelle under contract DE-AC05-76RLO 1830. PNNL technical report PNNL-SA-103824.

\section{References}

[1] Wittenberg LJ, EN Cameron, GL Kulcinski, SH Ott, JF Santarius, GI Sviatoslavsky, IN Sviatoslavsky, and H Thompson. 1991. "A Review of Helium-3 Sources and Acquisition for Use as Fusion Fuel," WCSAR-TR-AR3-9107. Fusion Technology, Special Issue on DHe3 Fusion, 21: 22302253.

[2] Kouzes, RT. 2009. “The ${ }^{3}$ He Supply Problem.” Technical Report PNNL-18388, Pacific Northwest National Laboratory, Richland, WA.

[3] Cooper RG. 2004. "SNS Detector Plans Nuclear Instruments and Methods." Physics Research A, 529: 394-398.

[4] Kouzes, RT, JH Ely, PE Keller, RJ McConn, and ER Siciliano. 2008. "Passive Neutron Detection for Interdiction of Nuclear Material at Borders." Nuclear Instruments and Methods in Physics Research Section A 584: 383-400.

[5] GAO. 2010. "The Helium-3 Shortage: Supply, Demand, and Options for Congress." Congressional Research Service. (21 September 2010).

[6] GAO. 2011. "Weaknesses in DOE's Management of Helium-3 Delayed the Federal Response to a Critical Supply Shortage.” Congressional Research Service. (May 2011).

[7] Gillo J. 2014 " The Isotope Program fills critical needs for 3He in the United States. An earlier shortage has been mitigated." National Isotope Development Center Newsletter (March 2014).

[8] Peurrung AJ. 2000. "Recent Development in Neutron Detection." Nuclear Instruments and Methods in Physics Research A, 443: 400-415. 
198

199

200

201

202

203

204

205

206

207

208

209

210

211

212

213

214

215

216

217

218

219

220

221

222

223

224

225

226

227

228

229

230

231

232

233

234

235

236

237

238

239

[9] Kouzes, RT, JH Ely, LE Erikson, WJ Kernan, AT Lintereur, ER Siciliano, DL Stephens, DC Stromswold, RM Van Ginhoven, and ML Woodring. 2010. "Neutron Detection Alternatives for Homeland Security." Nuclear Instruments and Methods in Physics Research A 623: 1035-1045.

[10] Kouzes, RT, JH Ely, AT Lintereur, EK Mace, DL Stephens, ML Woodring. 2011. "Neutron Detector Gamma Sensitivity Criteria," Nuclear Instruments and Methods in Physics Research A 654: 412-416.

[11] GAO. 2011b. "Neutron detectors: Alternatives to using helium-3." Congressional Research Service. (September 2011).

[12] Segrè E and C Wiegand. 1947. "Boron Trifluoride Neutron Detector for Low Neutron Intensities." Rev. Sci. Instrum, 18(86) DOI:10.1063/1.1740909.

[13] Kouzes, RT, JH Ely, AT Lintereur, ER Siciliano, ML Woodring. 2009. "BF 3 Neutron Detector Tests,” Technical Rpt. PNNL-19050, Pacific Northwest National Laboratory, Richland, WA.

[14] Dighe PM, DN Prasad, KR Prasad, SK Kataria, SN Athavale, AL Pappachan, and AK Grover. 2003. "Boron-Lined Proportional Counters With Improved Neutron Sensitivity," Nuclear Instruments and Methods in Physics Research A, 496: 154-161.

[15] Lintereur, AT, RT Kouzes, JH Ely, LE Erikson, ER Siciliano. 2009b. "Boron Lined Neutron Detector Measurements,” Technical Report PNNL-18938, Pacific Northwest National Laboratory, Richland, WA.

[16] Athanasiades A, NN Shehad, CS Martin, L Sun, and JL Lacy. 2005. "Straw Detector for High Rate, High Resolution Neutron Imaging." IEEE Nuclear Science Symposium Conference, San Juan, Puerto Rico, record N14-124: 623-627.

[17] Chen C, Y Yang, S Zhu, W Huang, H Gong, X Wang, Y Li. 2012. "Study of Boron-Lined StrawTube Detector Array for Neutron Scattering Measurement." 2012 IEEE Nuclear Science Symposium And Medical Imaging Conference Record (NSS/MIC). IEEE Nuclear Science Symposium Conference Record 176-179.

[18] Bliss M, RL Brodzinski, RA Craig, BD Geelhood, MA Knopf, HS Miley, RW Perkins, PL Reeder, DS Sunberg, RA Warner, and NA Wogman. 1995. "Glass-Fiber-Based Neutron Detectors For High- and Low-Flux Environments.” Proc. SPIE, 2551: 108.

[19] Seymour RS, B Richardson, M Morichi, M Bliss, RA Craig, and DS Sunberg. 2000. "ScintillatingGlass-Fiber Neutron Sensors, Their Application and Performance for Plutonium Detection and Monitoring," J. Radioanalytical and Nuclear Chemistry, 243: 387-388.

[20] Ely, JH, LE Erikson, RT Kouzes, AT Lintereur, ER Siciliano, 2009. “Lithium Loaded Glass Fiber Neutron Detector Tests,” Technical Report PNNL-18988, Pacific Northwest National Laboratory, Richland, WA.

[21] Katagiri M and M Matsubayashi. 2007. "Radiation or Neutron Detector Using Fiber Optics." United States Patent No. US7,214943 B2. Assignee Japan Atomic Energy Research, Kashiwa Japan.

[22] Nakamura T, T Kawasaki, T Hosoya, K Toh, K Oikawa, K Sakasai, M Ebine, A Birumachi, K Soyama, M Katagiri. 2012. "A large-area two-dimensional scintillator detector with a wavelength-shifting fibre readout for a time-of-flight single-crystal neutron diffractometer." Nuclear Instruments \& Methods In Physics Research Section A 686: 64-70.

[23] Ely JH, M Bliss, RT Kouzes, AT Lintereur, SM Robinson, ER Siciliano, MT Swinhoe, and ML Woodring. 2013. Final Technical Report for the Neutron Detection without Helium-3 Project. Technical Report PNNL-23011, Pacific Northwest National Laboratory, Richland, WA. 
[24] Lintereur, AT, JH Ely, RT Kouzes, LE Erikson, DC Stromswold. 2009. "Coated Fiber Neutron Detector Test," Technical Report PNNL-18919, Pacific Northwest National Laboratory, Richland, WA. [25] Boatner LA, JO Ramey, JA Kolopus, R Hawrami, WM Higgins, E van Loef, J Glodo, KS Shah, E Rowe, P Bhattacharya, E Tupitsyn, M Groza, A Burger, NJ Cherepy, PA Payne. 2013. "Bridgman growth of large $\mathrm{SrI}_{2}: \mathrm{Eu}^{2+}$ single crystals: A high-performance scintillator for radiation detection applications." Journal of Crystal Growth 379: 63-68. the CLYC detector for neutron and photon detection." Nuclear Instruments \& Methods In Physics Research Section A 736: 124-127.

[27] Holm P, K Perajarvi, S Ristkari, T Siiskonen, H Toivonen. 2014. "A capture-gated neutron spectrometer for characterization of neutron sources and their shields." Nuclear Instruments \& Methods In Physics Research Section A 751: 48-54.

[28] Ovechkina L, K Riley, S Miller, Z Bell, V Nagarkar. 2009. "Gadolinium loaded plastic scintillators for high efficiency neutron detection.” 2008 International Conference On Luminescence And Optical Spectroscopy Of Condensed Matter, Physics Procedia 2: 161-170.

[29] McGregor DS, SL Bellinger, JK Shultis. 2013. "Present status of microstructured semiconductor neutron detectors." Journal Of Crystal Growth 379: 99-110.

[30] Nelson, K, SL Bellinger, BW Montag, JL Neihart, TA Riedel, AJ Schmidt, DS McGregor. 2012. "Investigation of a lithium foil multi-wire proportional counter for potential He-3 replacement." Nuclear Instruments \& Methods In Physics Research Section A 669: 79-84.

[31] Fujiwara, T, H Takahashi, B Shi, N Torikai, N Yamada, M Uesaka. 2010. "2-Dimensional He-3 MMSGC with Floating Pads.” 2010 IEEE Nuclear Science Symposium Conference Record (NSS/MIC), IEEE Nuclear Science Symposium Conference Record 128-130.

[32] Jammes, C, N Chapoutier, P Filliatre, J-P Jeannot, F Jadot, D Verrier, A-C Scholer, B Bernardin. 2014. "Neutron flux monitoring system of the French GEN-IV SFR: Assessment of diverse solutions for in-vessel detector installation." Nuclear Engineering And Design 270: 273-282.

[33] Lavietes, A, R Plenteda, N Mascarenhas, LM Cronholm, M Aspinall, M Joyce, A Tomanin, P Peerani. 2012. "Liquid Scintillator-Based Neutron Detector Development." 2012 IEEE Nuclear Science Symposium And Medical Imaging Conference Record (NSS/MIC), IEEE Nuclear Science Symposium Conference Record 230-244.

[34] Pawelczak IA, AM Glenn, HP Martinez, ML Carman, NP Zaitseva, SA Payne. 2014. "Boron-loaded plastic scintillator with neutron-gamma pulse shape discrimination capability." Nuclear Instruments \& Methods In Physics Research Section A 751: 62-69.

[35] Chandra R, G Davatz, H Friederich, U Gendotti, D Murer. 2012. "Fast neutron detection with pressurized He-4 scintillation detectors." Journal Of Instrumentation 7, Article C03035.

[36] Archambault S, F Aubin, M Auger, M Beleshi, E Behnke, J Behnke, B Beltran, K Clark, X Dai, M Das, A Davour, F Debris, J Farine, M-H Genest, G Giroux, R Gornea, R Faust, H Hinnefeld, A Kamaha, C Krauss, M Lafreniere, M Laurin, I Lawson, C Leroy, C Levy, L Lessard, I Levine, J-P Martin, S Kumaratunga, SR MacDonald, P Nadeau, A Noble, M-C Piro, S Pospisil, N Starinski, I Stekl, N Vander Werf, U Wichoski, V Zacek. 2011. "New insights into particle detection with superheated liquids." New Journal Of Physics 13, Article: 043006. 


\section{Figure Captions}

283 Figure 1. Supply scenario based on $<10 \mathrm{~kL} / \mathrm{y}$ allotted, where the vertical axis is liters (from Jehanne Gillo, 284 DOE Office of Nuclear Physics)

285

286

287

288 


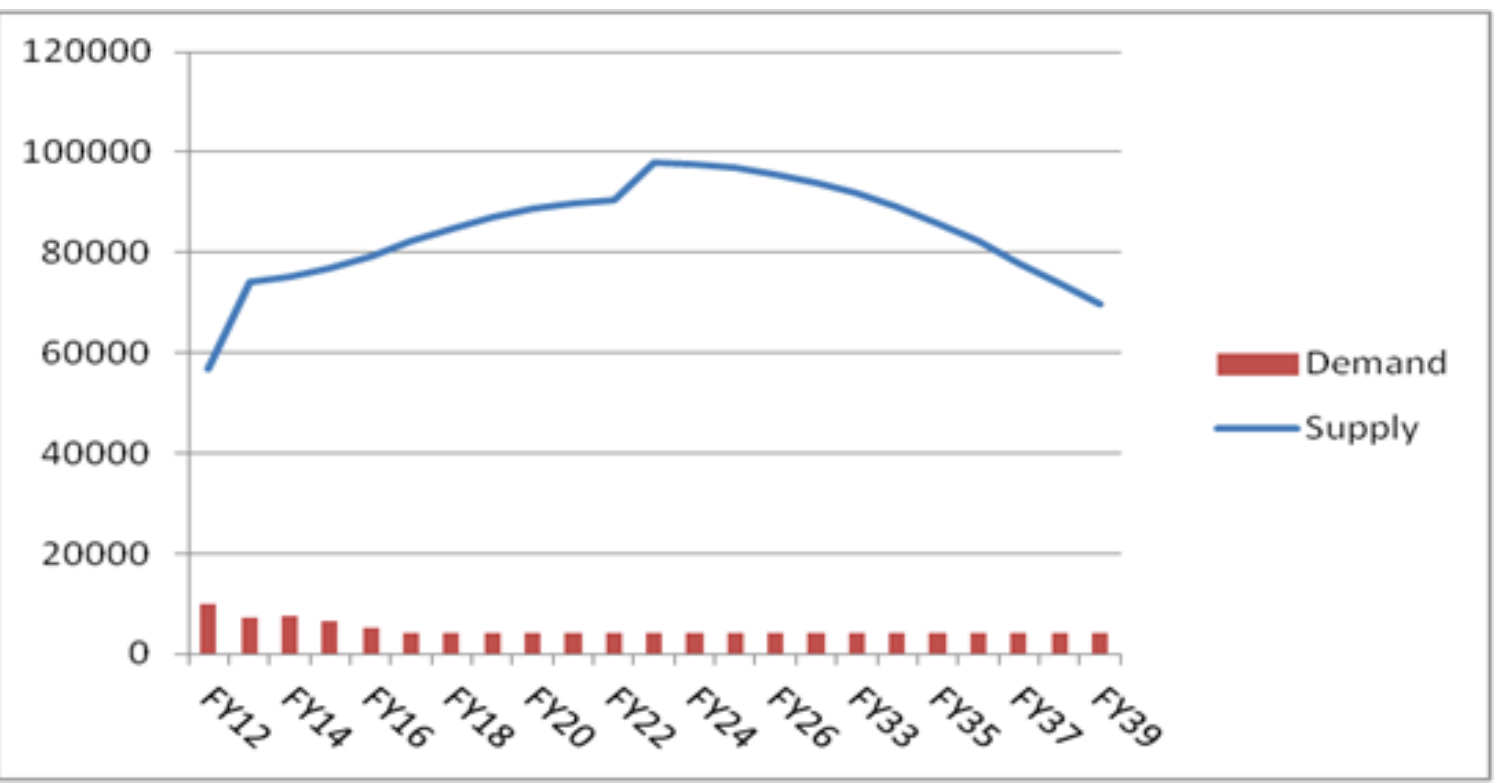

Figure 1. Supply scenario based on $<10 \mathrm{~kL} / \mathrm{y}$ allotted, where the vertical axis is liters (from Jehanne Gillo, DOE Office of Nuclear Physics)

297

298

299

300

301

302 